\title{
SEGREGAÇÃO RESIDENCIAL E POLÍTICAS PÚBLICAS São Paulo na década de 1990
}

\section{Haroldo da Gama Torres}

\section{Introdução}

Grande parte das literaturas sociológica e urbanística brasileiras toma a segregação residencial como um fato incontestável. De um lado, a forte heterogeneidade de renda e de condições sociais entre os bairros e os distritos das metrópoles brasileiras dão base lógica a tal proposição (Villaça, 2001; Taschner e Bógus, 2000; Ribeiro e Telles, 2000). De outro, o grande tamanho da população favelada e seu crescimento no período recente servem também de inspiração ao argumento de que a segregação seria um fenômeno real e cada vez maior (Kowarick, 2001). Numa outra perspectiva, o crescimento dos chamados condomínios fechados, bem como o aumento dos aparatos de segurança e exclusão existentes nos bairros e pré-

Artigo recebido em fevereiro/2003

Aprovado em novembro/2003 dios de alta renda, também têm sido utilizados como evidência de uma sociedade cada vez mais segregada residencialmente (Caldeira, 2000).

Paradoxalmente, a segregação residencial existente nas cidades brasileiras quase nunca foi medida em termos empíricos, no que pese a longa tradição internacional de medir o fenômeno, sobretudo nos Estados Unidos (Massey e Denton, 1993; Mingione, 1999; Wilson, 1990). ${ }^{1}$ O desinteresse por tal comparação pode ser talvez ser explicado pelo fato de a tradição norte-americana de estudos de segregação ser nitidamente voltada para a questão racial, enquanto no Brasil o debate sempre se focou nos aspectos habitacionais e socioeconômicos mais gerais. No entanto, esse tipo de estudo empírico tem também se tornado freqüente em outros países latino-americanos, como, por exemplo, o Chile (Sabatini, 2001) e o México (Schteingart, 1987), sugerindo que medidas de segregação que permitam análises comparativas podem dar uma noção mais 
precisa dos níveis de segregação existentes em cada país e a sua evolução recente.

Nesse sentido, este artigo é organizado em torno de dois objetivos principais. Em primeiro lugar, pretendemos discutir por que a segregação residencial é importante do ponto de vista das políticas sociais. Em segundo, buscamos medir a evolução da segregação residencial na região metropolitana de São Paulo na última década. Trabalharemos aqui com o índice de dissimilaridade, indicador amplamente utilizado em estudos de segregação residencial (Massey e Denton, 1993; Briggs, 2001; Sabatini, 2001). Utilizaremos também diferentes escalas geográficas (setores censitários e distritos), de forma a tentar distinguir como as chamadas micro e macro segregação variaram no período. ${ }^{2}$

Apresentamos na primeira seção uma discussão sobre o significado da segregação para as políticas públicas, bem como o problema de como medir o fenômeno. A seguir, apresentamos diferentes alternativas de estimativa para o índice de dissimilaridade em São Paulo, tanto na escala de distritos do IBGE, como na escala de setores censitários. Mostraremos que a segregação residencial aumentou substancialmente, tomando como referência a distância entre as famílias cujos responsáveis tinham entre zero e três salários mínimos e entre vinte salários mínimos e mais. ${ }^{3}$ Adiante, tratamos de observar como o fenômeno se distribuiu no interior da região metropolitana de São Paulo. Ao final, extraímos algumas conseqüências analíticas desses resultados.

\section{Segregação e politicas públicas}

O que é segregação residencial? Tratado de forma genérica, é o grau de aglomeração de um determinado grupo social/étnico em uma dada área. ${ }^{4}$ Nesse sentido, a formação de condomínios fechados de alta renda - como os da Barra (Rio de Janeiro) ou os de Alphaville (São Paulo) - poderia ser considerada uma forma de auto-segregação.

Peter Marcuse (2001), porém, defende uma definição mais rigorosa do fenômeno, considerando-o o processo por meio do qual uma determinada população é forçada de modo involuntário a se agrupar em uma dada área. ${ }^{5}$ Entre os compo- nentes que induziriam essa aglomeração forçada estariam tanto mecanismos de mercado - que induzem à valorização ou à desvalorização imobiliária de determinadas áreas - como instrumentos institucionais (taxação, investimentos públicos, remoção de favelas etc.) e práticas efetivas de discriminação (por exemplo, por parte de agentes imobiliários). ${ }^{6}$

Essa definição também ressalta o aspecto, algumas vezes menosprezado, de que a segregação é - sobretudo - um fenômeno relacional: só existe segregação de um grupo quando outro grupo se segrega ou é segregado. É nesse componente relacional que as medidas de segregação vão se basear, buscando medir o grau de isolamento de um determinado grupo social em relação a outro.

Cabe também discutir com alguma profundidade por que a segregação residencial é importante do ponto de vista das políticas sociais. De modo geral, seis elementos principais podem ser apresentados como evidência de que a segregação residencial contribui para o aumento e/ou a perpetuação da pobreza:

- Má qualidade residencial, riscos ambientais e para a saúde: A principal maneira por meio da qual as famílias de menor renda lidam com a disputa pelo espaço urbano no mercado de terras tem a ver com a busca por residências e/ou áreas desvalorizadas, isto é, domicílios pequenos, pior dotados de infra-estrutura urbanística e, muitas vezes, sujeitos a riscos de diversos tipos relacionados à ausência de saneamento e a problemas ambientais como inundações e deslizamentos. ${ }^{8}$ Evidências para outros países indicam que os custos diretos associados à perda de horas de trabalho devido a doenças, bem como os gastos com medicamentos e procedimentos médicos, contribuam substancialmente para a redução da renda disponível para o consumo, acentuando a pobreza, a mortalidade e a instabilidade econômica da família (Yinger, 2001). No caso do Brasil, os gastos com saúde são regressivos, incidindo mais acentuadamente sobre os mais pobres (Gráfico 1). Isso significa que riscos para a saúde decorrentes das condições de moradia contribuem adicionalmente para agravar essa situação de regressividade. 
- Custos de moradia desproporcionais: De modo geral, famílias mais pobres tendem a apresentar um gasto com moradia (como proporção da renda) superior ao de famílias de classe média e alta. Segundo a pesquisa de orçamento familiar (POF96) do IBGE, por exemplo, enquanto os gastos com habitação correspondem a $24,9 \%$ dos gastos das famílias com rendimento familiar inferior a dois salários mínimos, essa proporção é declinante segundo a renda, atingindo $17,7 \%$ para as famílias com renda familiar superior a trinta salários mínimos (Gráfico 1). Como conseqüência, a renda disponível para o consumo de alimentos e outros bens e serviços é proporcionalmente menor, contribuindo para o empobrecimento relativo dessas famílias. Em outras palavras, ao contrário do que se poderia imaginar, a segregação da população em favelas e periferias - em média - não contribui para contrabalançar a regressividade dos custos de moradia, provavelmente devido à escassez de espaço disponível (ao preço que essas famílias podem pagar) e o conseqüente aumento de seu custo relativo. ${ }^{9}$
- Efeitos de vizinhança: Diversos estudos evidenciam que crescer em bairros com alta concentração de pobreza tem efeitos negativos relevantes em termos de avanço educacional, emprego, gravidez na adolescência e atividade criminal (Duralauf, 2001; Briggs, 2001; Cardia 2000). Embora os mecanismos que explicam a relação entre pior desempenho educacional e residência em locais de elevada concentração de pobres, por exemplo, não sejam bem conhecidos, é evidente que o pior desempenho educacional nessas áreas contribui para perpetuar e reproduzir a pobreza a longo prazo. Por outro lado, na medida em que a rede de relações sociais de um indivíduo ou família contribui para seu acesso a empregos e a serviços públicos, o isolamento social presente nas áreas segregadas tende a contribuir significativamente para a redução das oportunidades das famílias residentes nesses locais.

- Distância entre moradia e emprego: Este fenômeno, identificado na literatura internacional como spatial mismatch, diz respeito à baixa fre-

Gráfico 1

Gastos em Saúde e Educação Segundo Faixa de Renda Familiar, Regiões Metropolitanas Brasileiras, 1996.

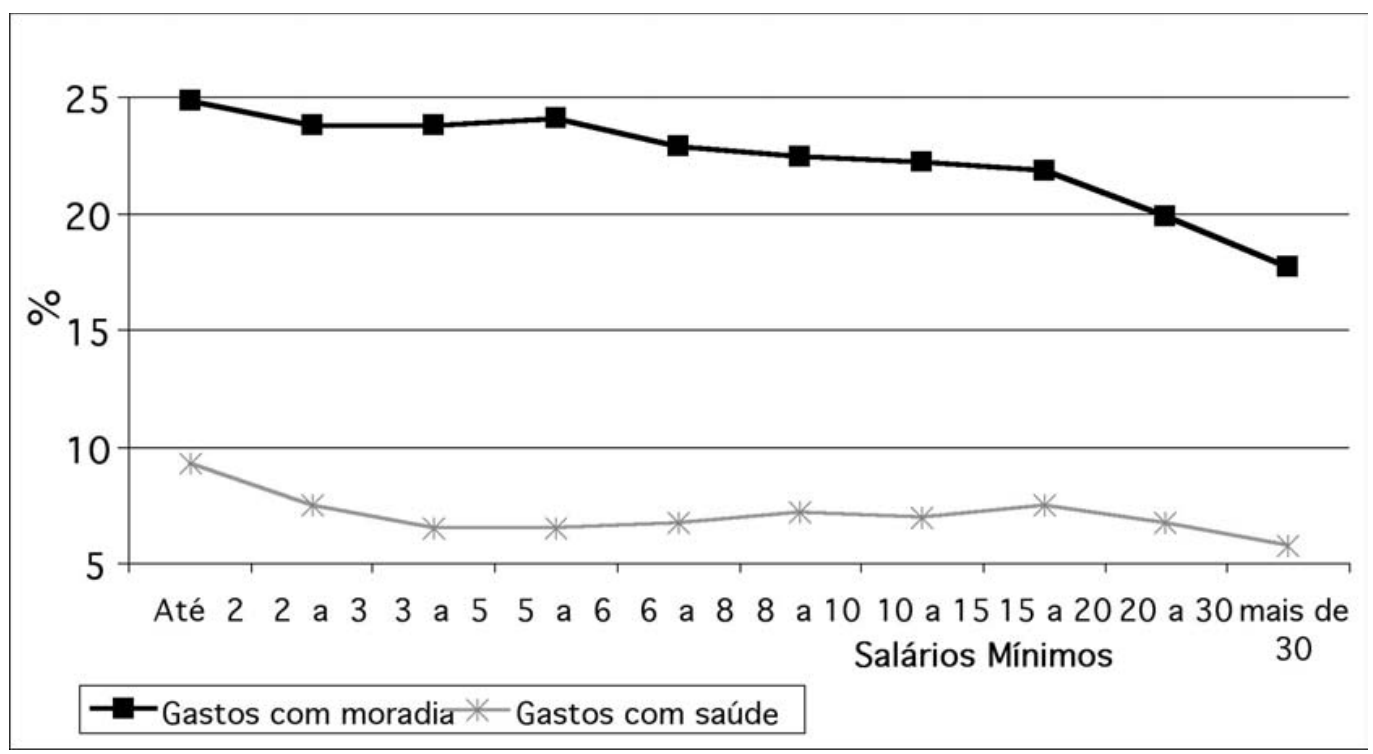

Fonte: IBGE, Pesquisa de Orçamento Familiar (POF), 1996. 
qüência de empregos nos locais de moradia da população de baixa renda (Kasarda, 1993). No caso da região metropolitana de São Paulo, por exemplo, a maior parte do emprego nos setores dinâmicos de comércio e serviços concentra-se num número restrito de distritos do Centro e ao longo do corredor Sul-Sudoeste do município de São Paulo (Jardim Paulista, Itaim, Pinheiros, Moema e Vila Mariana). A maior parte desses distritos é ocupado por moradores de média e alta renda (Emplasa, 1994). Além disso, o deslocamento espacial entre empregos e moradia foi acentuado pela significativa perda de empregos industriais na Zona Leste de São Paulo e nos municípios do ABC. Como conseqüência, a moradia em periferias distantes e em cidades-dormitórios além de aumentar os custos de transporte - com impactos para a renda disponível e conforto dos moradores - trás também efeitos sobre o acesso à informação sobre postos de trabalho, bem como eleva substancialmente os custos de procurar emprego.

- A moradia em situação irregular: A posse irregular da terra, em favelas ou loteamentos clandestinos, induz pior acesso a serviços públicos. Tal fenômeno ocorre porque a provisão de serviços públicos nesses locais tende a ser problemática, uma vez que - em muitos casos - a oferta de serviços depende da existência de terras pertencentes ao Estado (ou passíveis de aquisição), disponíveis para a construção de escolas, infra-estrutura urbana e outros equipamentos sociais (Maricato, 1996).

- A moradia como fator de geração de renda: Por diversas razões, a moradia pode ser também entendida como um fator de geração de renda. Espaço residencial pode ser utilizado para fins produtivos: cômodos podem ser alugados; produtos podem ser estocados; a casa pode ser o locus de produção de roupas, alimentos e serviços; a casa pode ser utilizada como ponto de venda. Além disso, em algumas circunstâncias, a casa pode ser usada como garantia para empréstimos passíveis de serem utilizados para fins produtivos.10 Todas essas possibilidades são menos prováveis em locais muito segregados, em virtude da fragilidade do mercado local, da ausência de espaço disponí- vel, da precariedade tanto de residências como do status jurídico dos domicílios.

Em suma, existe grande evidência na literatura de que, por diferenciados mecanismos, a segregação espacial contribui para a reprodução da pobreza e de problemas sociais nas áreas de emprego, educação, habitação, saúde, transportes, geração de renda e segurança pública. Daí a sua centralidade para o debate metropolitano no Brasil e a importância de mensurar o fenômeno para compreender sua evolução ao longo do tempo.

\section{Medidas de segregação}

De modo geral, o conceito de segregação remete-se a duas dimensões principais: os padrões de concentração espacial de determinados grupos sociais e o grau de homogeneidade social de determinadas áreas. ${ }^{11}$ Essas dimensões são medidas por meio de indicadores baseados na composição da população de cada área estudada. Provavelmente, o indicador mais utilizado neste campo é o índice de dissimilaridade, embora outras medidas, como os chamados "índices de isolamento", sejam também utilizadas (Sabatini, 2001; Massey e Denton, 1993).

O índice de dissimilaridade mede a proporção da população (de um dado grupo social) que teria de mudar para que a distribuição de cada grupo social em cada área fosse similar a essa distribuição para o conjunto da cidade. ${ }^{12}$ No geral, um índice de 0 a 30\% implica uma segregação suave, de 30 a 60\% uma moderada e de mais de 60\% uma severa (Massey e Denton, 1993; Briggs, 2001). Trata-se, porém, de um indicador relativamente limitado e que pode ser criticado de duas maneiras:

- O indicador não capta a segregação no interior das zonas utilizadas como unidade de análise (distritos, bairros etc.). A população de um dado grupo social pode viver no interior de um único condomínio ou dispersa por todo distrito, e o indicador é o mesmo para aquele distrito.

- O indicador varia segundo o tamanho da unidade de análise. Geralmente, o nível de dissimila- 
ridade tende a ser mais baixo para áreas grandes (como distritos) do que para áreas menores (como setores censitários), no chamado problema do grid (Sabatini, 2001). ${ }^{13}$

De qualquer modo, para tentar controlar esses problemas, adotaremos aqui dois procedimentos principais. Trabalhar com a menor unidade de análise possível (no caso o setor censitário), de modo a tentar minimizar o problema da distribuição da população no interior de cada área. Calcular os índices de dissimilaridade tanto para setores censitários, como para distritos, de modo a considerarmos o problema do grid.

Apesar dessas dificuldades, este indicador tem sido bastante utilizado, sendo capaz de evidenciar, por exemplo, os altíssimos níveis de segregação residencial de negros e brancos em todas as grandes cidades norte-americanas, com níveis mais elevados para Chicago, Detroit e Kansas City (Massey e Denton, 1993). A utilização de setores censitários como unidade de análise também permitiu mostrar que essa forma segregação se manteve elevada entre os anos de 1940 e 1990, com uma única exceção para a queda relativa ob- servada na cidade de São Francisco. Apresentamos a seguir os resultados observados para São Paulo em 1991 e 2000, tendo por referência a chamada segregação socioeconômica e não a racial. ${ }^{14}$

\section{Avaliação da segregação residencial em São Paulo}

O que tentaremos medir aqui é a evolução da segregação residencial nos anos de 1990 tendo por referência a separação entre famílias cujos chefes têm alta e baixa renda e entre famílias cujos chefes têm alta e baixa escolaridade. Calcularemos a medida tanto para distritos como para setores censitários nos anos de 1991 e 2000.

Todavia, antes de apresentarmos os resultados propriamente ditos, vale a pena discutir como os indicadores de rendimento e escolaridade disponíveis na escala de setores censitários - variaram no período nos 21 municípios da mancha urbana de São Paulo considerados na análise. ${ }^{15}$ Apresentamos na Tabela 1 a evolução da renda

Tabela 1

Distribuição dos Chefes de Domicilio da Mancha Urbana de São Paulo, Segundo Escolaridade e Renda, 1991 e 2000

\begin{tabular}{llll}
\hline Renda do chefe de domicílio & Total & Distribuição* & Distribuição** \\
\hline $\mathbf{1 9 9 1}$ & & & 39,09 \\
0 a 3 salários mínimos & 1.457 .507 & 31,82 \\
3 a 10 salários mínimos & 1.438 .649 & 31,28 \\
10 a 15 salários mínimos & 262.094 & 7,52 \\
15 a 20 salários mínimos & 115.282 & 3,31 \\
20 salários mínimos e mais & 211.556 & 3,09 & 6,07 \\
Sem rendimento/não informa & 243.561 & 5,67 & - \\
Total & 3.728 .649 & 6,53 & 100,00 \\
& & 100,00 & \\
2000 & & & 35,43 \\
3 a 10 salários mínimos & 1.457 .854 & 34,71 \\
10 a 15 salários mínimos & 1.839 .584 & 31,44 & 6,56 \\
15 a 20 salários mínimos & 269.950 & 39,67 & 5,00 \\
20 salários mínimos e mais & 205.548 & 5,82 & 8,31 \\
Sem rendimento/não informa & 341.990 & 4,43 & - \\
Total & 522.384 & 7,37 & 100,00 \\
\hline
\end{tabular}

*Considera os chefes de domicílio sem rendimento.

**Não considera os chefes de domicílio sem rendimento.

Fonte: IBGE, Censos Demográficos de 1991 e 2000. 
dos chefes de domicílio nos anos de 1990. Podemos observar que a proporção de chefes com zero a três salários mínimos de rendimento mensal caiu substancialmente de 41,8 para $35,4 \%$, enquanto crescia ligeiramente a proporção de chefes com mais de dez, mais de quinze e mais de vinte salários mínimos. Provavelmente essa evolução está subestimada em valores reais, uma vez que o salário mínimo apresentou alguma apreciação depois do Plano Real. ${ }^{16}$ De todo modo, é preciso tomar algum cuidado com essa comparação em função diferença entre os critérios de captação da informação sobre os "sem rendimento" entre os censos de 1991 e $2000 .^{17}$

Os dados censitários também indicam que, para a década de 1990, a proporção de chefes com menos de três anos de estudo caiu de 24,5 para 19,3\%. Analogamente, a proporção de chefes com onze anos de escolaridade ou mais (segundo grau completo) passou de 24,7 para $31 \%$, embora a proporção de chefes com superior completo (quinze anos de estudo e mais) tenha ficado praticamente estagnada, de 10,61 em 1991 para 11,32\% em 2000.

Em outras palavras, ao longo da década, a população de baixíssima escolaridade e de baixíssima renda parece ter caído significativamente na região metropolitana de São Paulo. Esses dados são consistentes com os indicadores educacionais mais gerais e com os dados de rendimento disponíveis a partir de outras fontes de dados, como a PED e as PNADs e a PME.
No entanto, nem sempre a redução dos níveis de pobreza implica a redução da segregação. Massey e Denton (1993), por exemplo, defendem o argumento de que entre 1910 e 1940 a segregação residencial aumentou substancialmente nos Estados Unidos, no que pese a significativa elevação dos níveis de renda. No caso de São Paulo, quando consideramos - para a escala de setores censitários - os índices de dissimilaridade por renda entre chefes com zero a três salários mínimos e aqueles com mais de vinte, podemos observar que a segregação aumentou significativamente, passando de 71,9 para 77,0 entre 1991 e 2000 (Tabela 2). ${ }^{18}$

Além da importância do crescimento da segregação, como indicador de deterioração das relações sociais na cidade na década de 1990, vale destacar que os níveis observados são muito impressionantes, superiores à dissimilaridade entre negros e brancos existente em Nova York em 1980 (Massey e Denton, 1993), embora essa comparação deva ser tomada com ressalvas. ${ }^{19}$ Além do mais, quando consideramos a dissimilaridade para outros estratos de renda, como para as faixas de zero a três e dez salários mínimos e mais, observamos que - também neste caso - os níveis são elevados (indicando severa segregação) e cada vez maiores ao longo da década. Em outras palavras, o fenômeno do isolamento social parece não ter se restringido apenas aos extremos da distribuição de renda, mas também a estratos intermediários de classe média.

Tabela 2

Índices de Segregação Residencial (Dissimilaridade) Segundo Diferentes Grupos de Escolaridade e Renda, na Escala de Setores Censitários, Mancha Urbana de São Paulo, 1991 e 2000*

\begin{tabular}{lll}
\hline Dissimilaridade Residencial & 1991 & 2000 \\
\hline Dissimilaridade entre chefes de 0 a 3 e 10 e mais salários mínimos & 58,43 & 63,92 \\
Dissimilaridade entre chefes de 0 a 3 e 15 e mais salários mínimos & 66,90 & 71,08 \\
Dissimilaridade entre chefes de 0 a 3 e 20 e mais salários mínimos & 71,86 & 76,97 \\
Dissimilaridade entre chefes de 0 a 3 e 11 e mais anos de estudo & 57,48 & 51,64 \\
Dissimilaridade entre chefes de 0 a 3 e 15 e mais anos de estudo & 70,76 & 71,32 \\
Total de setores censitários & 14.114 & 20.127 \\
\hline
\end{tabular}

*As estimativas de dissimilaridade foram realizadas a partir dos setores censitários de 1991 e 2000.

Fonte: IBGE, Censos Demográficos de 1991 e 2000. 
Os dados de segregação por estrados educacionais, no entanto, narram uma outra história. A segregação cresceu ligeiramente entre as famílias com chefes com curso superior (quinze anos de estudo e mais) e aquelas cujos chefes tinham baixa escolaridade (até três anos). Porém, ela caiu substancialmente, de 57,5 para 51,6, na comparação entre chefes com até três anos de estudo e aqueles com segundo grau completo (onze anos de estudo e mais). ${ }^{20}$

De um lado, observamos o aumento da segregação residencial quando tomamos renda como parâmetro; de outro, observamos sua redução tendo por referência a escolaridade. Esse fenômeno parece ser reflexo do aumento substancial da escolaridade ocorrido na região metropolitana de São Paulo na década de 1990 (Alesp, 2000), fazendo com que, cada vez mais, pessoas com segundo grau passassem a residir em bairros populares. No entanto, esse movimento não se traduziu em mudança efetiva dos padrões de segregação socioeconômica medidos por rendimento.

Quando tratamos de medir a segregação numa outra escala - a de distritos -, observamos movimentos semelhantes. A segregação cresce segundo os parâmetros de rendimento, e cai segundo os parâmetros de escolaridade (Tabela 3). Como era esperado, os níveis de segregação são mais baixos neste caso, em função da variação da escala de observação. Cabe destacar que distritos são unidades espaciais de grande porte, podendo conter em seu interior uma heterogeneidade espacial relevante (como a ocorrência de favelas) não captadas pela medida nesta escala. ${ }^{21}$ Mesmo assim, os níveis observados ainda são relativamente elevados, sobretudo quando consideramos a dissimilaridade entre os chefes de zero a três salários mínimos e os de vinte salários mínimos e mais.

Ao contrário do observado em Santiago ( $\mathrm{Sa}$ batini, 2001), onde foram constatados queda na macrosegregação e aumento na microsegregação, em São Paulo a segregação medida por rendimentos aumentou nas duas escalas. Essas medidas sugerem um crescente isolamento social, tanto na comparação entre grandes áreas, como localmente, no interior de cada distrito. Indicam também a extensão e a profundidade do fenômeno.

Em síntese, os resultados aqui apresentados apontam uma evolução complexa da "situação social" paulistana na década de 1990. De um lado, observamos redução da pobreza e da proporção de chefes de família com baixíssima escolaridade. De outro, constatamos um aumento substancial da segregação residencial, quando observada por parâmetro de renda. Esse fenômeno não é de todo inesperado para a região metropolitana de São Paulo. De fato, a década de 1990 foi sempre contraditória em relação a outros indicadores sociais, com melhora significativa em alguns deles (como educação e saneamento) e deterioração relevante de outros (como desemprego e violência) (Alesp, 2000).

Tabela 3

Índices de Segregação Residencial (Dissimilaridade) Segundo Diferentes Grupos de Escolaridade e Renda, na Escala de Distritos, Mancha Urbana de São Paulo, 1991 e 2000

\begin{tabular}{lll}
\hline Dissimilaridade Residencial & 1991 & 2000 \\
\hline Dissimilaridade entre chefes de 0 a 3 e 10 e mais salários mínimos & 41,88 & 45,64 \\
Dissimilaridade entre chefes de 0 a 3 e 15 e mais salários mínimos & 50,46 & 52,49 \\
Dissimilaridade entre chefes de 0 a 3 e 20 e mais salários mínimos & 55,77 & 58,80 \\
Dissimilaridade entre chefes de 0 a 3 e 11 e mais anos de estudo & 41,21 & 34,67 \\
Dissimilaridade entre chefes de 0 a 3 e 15 e mais anos de estudo & 54,42 & 52,99 \\
Total de distritos & 132 & 132 \\
\hline
\end{tabular}




\section{Hipóteses sobre a evolução observada nos anos de 1990}

Para justificar o aumento da segregação observado para a década de 1990, poderíamos com base na literatura - formular três hipóteses diferentes, não excludentes:

- Incremento no padrão de auto-isolamento dos grupos de renda mais elevada: Tal hipótese pode ser derivada, por exemplo, do trabalho de Caldeira (2000), que aponta para o impacto do crescimento de condomínios e áreas fechadas, sobretudo na porção Oeste da região metropolitana..22

- Maior grau de isolamento da população favelada: Este argumento foi utilizado por Kowarick (2001), por exemplo. Porém, deve-se chamar a atenção para o fato de que o crescimento demográfico das favelas não pode ser utilizado per si como indicador de segregação. Se esse crescimento é acompanhado de uma maior heterogeneidade social das favelas, por exemplo, ele pode implicar em redução da segregação, ao menos nos termos de um indicador como o índice de dissimilaridade. ${ }^{23}$
- Continuidade do processo de periferização: Tem-se observado esse processo com o consistente aumento da população de municípios e distritos mais afastados do centro de São Paulo (Villaça, 1999). Trata-se de um fenômeno em curso deste os anos de 1950, mas a partir da década de 1970 os distritos centrais passaram a apresentar taxas negativas de crescimento, enquanto os distritos da periferia urbana continuaram a apresentar taxas elevadas. ${ }^{24}$ No entanto, nem sempre o crescimento demográfico implica maior segregação.

Para discutir com mais profundidade esses elementos, apresentamos no Mapa 1 e na Tabela 4 a distribuição dos setores censitários da mancha urbana de São Paulo, classificados segundo o estrato de renda predominante dos chefes de domicílio desse setor. ${ }^{25}$

Do ponto de vista espacial, podemos observar que as famílias cujos chefes têm renda superior a dez salários mínimos são localizadas de forma predominante no centro da metrópole, o que é consistente com o modelo centro-periferia (Villaça, 2001). Observa-se, no entanto, uma importante he-

Mapa 1

Setores Censitários Classificados Segundo o Grupo de Renda Predominante do Chefe de Domicílio, Mancha Urbana de São Paulo, 2000

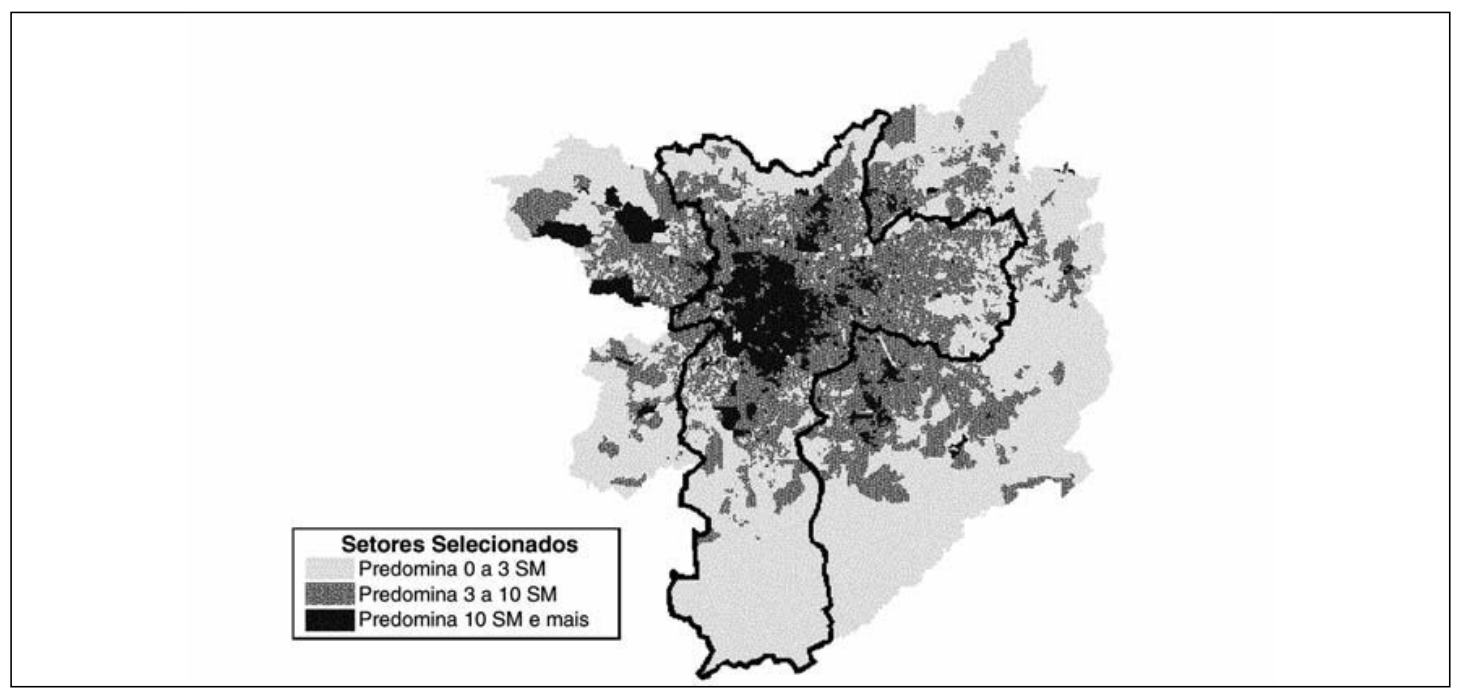

Fonte: IBGE, Censo Demográfico 2000. 
Tabela 4

Distribuição dos Chefes do Domicílio da Região Metropolitana de São Paulo, Segundo Faixas de Rendimentos do Chefe e Segundo o Tipo de Setor Censitário Predominante, 1991 e 2000

\begin{tabular}{|c|c|c|c|c|}
\hline \multirow[b]{2}{*}{$\begin{array}{l}\text { Tipo de setor censitário } \\
\text { 1991* }\end{array}$} & \multicolumn{3}{|c|}{ Proporção de chefes com: } & \multirow[t]{2}{*}{ Total } \\
\hline & 0 a 3 s.m. & 3 a 10 s.m. & 10 s.m. e mais & \\
\hline Predomínio de chefes de 0 a 3 & 32,73 & 18,63 & 4,32 & 22,11 \\
\hline Predomínio de chefes de 3 a 10 & 60,93 & 68,81 & 47,08 & 61,84 \\
\hline Predomínio de chefes de 10 e mais & 6,34 & 12,56 & 48,60 & 16,05 \\
\hline Total & 100,00 & 100,00 & 100,00 & 100,00 \\
\hline \multicolumn{5}{|l|}{2000} \\
\hline Predomínio de chefes de 0 a 3 & 46,95 & 24,28 & 4,26 & 28,33 \\
\hline Predomínio de chefes de 3 a 10 & 49,73 & 66,04 & 44,76 & 56,03 \\
\hline Predomínio de chefes de 10 e mais & 3,32 & 9,69 & 50,98 & 15,63 \\
\hline Total & 100,00 & 100,00 & 100,00 & 100,00 \\
\hline
\end{tabular}

*Identificamos por geoprocessamento os setores de 1991 que correspondem (por sobreposição cartográfica) a cada um dos tipos de setor censitário, conforme a divisão proposta para 2000 no Mapa 1.

Fonte: IBGE, 1991 e 2000.

terogeneidade, dada pela significativa presença de núcleos de maior renda nos bairros de Santana e Tatuapé, bem como nos núcleos dos municípios do $\mathrm{ABC}$ e de Guarulhos e nos condomínios dos municípios do Oeste da região metropolitana (Marques e Bitar, 2002).

De modo análogo, os grupos de renda intermediária localizam-se num anel intermediário, e os grupos de menor renda ao longo de todo anel periférico. Cabe porém destacar a significativa presença de áreas de baixa renda incrustadas ao longo de todo anel intermediário, elemento que pode ser explicado em função da presença de setores subnormais (favelas) tanto no anel intermediário como no periférico.

A rigor, a divisão da região metropolitana nestes três grupos de setores censitários permitenos refletir com mais profundidade a respeito dos processos subjacentes ao aumento da segregação observado na seção anterior. Esses resultados podem ser observados na Tabela 4.

Podemos observar que, na comparação entre 1991 e 2000, a proporção de chefes com mais de dez salários mínimos que residem em setores predominantemente ocupados por famílias per- tencentes a este grupo de renda cresceu de 48,6 para 50,9\%. Em outras palavras, as áreas mais ricas da região tornaram-se um pouco mais "exclusivas" no período, em função da redução da proporção de famílias cujos chefes tinham entre três e dez salários mínimos. Esses resultados parecem consistentes com a hipótese proposta por Caldeira (2000), relacionada ao aumento da auto-segregação dos mais ricos. ${ }^{26}$

Por outro lado, nas áreas predominantemente ocupadas por famílias cujos chefes recebiam entre zero e três salários mínimos, observou-se um aumento substancial da participação das famílias mais pobres, sendo que a proporção de pobres residindo neste tipo de setor passou de 32,7 para $46,9 \% .{ }^{27}$ Isso quer dizer que as áreas com predominância de pessoas muito pobres se tornaram menos diversificadas socialmente. Ou seja, esses dados mostram que o crescimento demográfico observado na periferia de fato contribuiu para o aumento da proporção de pobres neste tipo de área, conforme a hipótese sugerida por Villaça (1999).

Para melhor interpretar os resultados, apresentamos a seguir o mesmo problema em termos do indicador de dissimilaridade (Tabela 5). Para 
Tabela 5

Distribuição da Dissimilaridade Segundo o Tipo de Setor Censitário, 1991 e 2000

\begin{tabular}{|c|c|c|c|c|c|}
\hline \multirow[t]{2}{*}{ Ano } & \multirow[t]{2}{*}{ Dissimilaridade Total } & \multirow{2}{*}{$\begin{array}{l}\text { Contribuição } \\
\text { dos setores } \\
\text { subnormais }\end{array}$} & \multicolumn{3}{|c|}{$\begin{array}{l}\text { Contribuição dos setores normais* com } \\
\text { predominio de chefes com: }\end{array}$} \\
\hline & & & 0 a 3 s.m. & 3 a 10 s.m. & 10 s.m. e + \\
\hline \multicolumn{6}{|c|}{ Dissimilaridade entre 0 a 3 e 10 salários mínimos e mais } \\
\hline 1991 & 58,43 & 4,77 & 9,89 & 22,36 & 21,42 \\
\hline 2000 & 63,92 & 7,20 & 14,17 & 18,72 & 23,83 \\
\hline \multicolumn{6}{|c|}{ Dissimilaridade entre 0 a 3 e 20 salários mínimos e mais } \\
\hline 1991 & 71,86 & 4,91 & 10,75 & 25,27 & 30,94 \\
\hline 2000 & 76,97 & 7,37 & 15,28 & 20,44 & 33,88 \\
\hline
\end{tabular}

*Identificamos por geoprocessamento os setores de 1991 que correspondem (por sobreposição cartográfica) a cada um dos tipos de setor censitário, conforme a divisão proposta para 2000 no Mapa 1.

Fonte: IBGE, 1991 e 2000.

isso, lançamos mão da chamada "contribuição de cada área para a dissimilaridade". ${ }^{28}$

De fato, quando tomamos - nos setores normais - o índice de dissimilaridade para os dois extremos da distribuição de renda, podemos observar que a contribuição para a segregação dos setores predominantemente pobres aumentou entre $1991 \mathrm{e}$ 2000, ao mesmo tempo em que também crescia a contribuição da segregação nos setores predominantemente ricos. Quando tomamos isoladamente os setores subnormais (favelas), podemos também observar que esse grupamento contribuiu também para o aumento da segregação residencial no período.

Em termos absolutos, a maior contribuição para a dissimilaridade é dada pelos setores censitários com elevadas proporções de famílias mais ricas. No entanto, observou-se um maior crescimento do grau de isolamento social das populações de favela e periferia, reforçando sua relevância na explicação da elevação dos níveis de segregação residencial na região metropolitana de São Paulo ao longo da década de 1990. As áreas de renda intermediária - aqui caracterizada pelas áreas com predomínio de famílias de três a dez salários mínimos (Mapa 1) - continuam sendo importantes para explicação dos elevados níveis de segregação, mas seu impacto foi reduzido na última década.

\section{Conclusão}

De certa forma, os resultados aqui apresentados permitem a inserção do tema da segregação no âmbito do debate sobre a chamada "década perdida". Vários autores discutiram o paradoxo da melhora dos indicadores sociais nos anos de 1980 vis-à-vis a dinâmica negativa da economia brasileira. ${ }^{29}$ O fenômeno foi explicado em função da ação dos movimentos sociais e, sobretudo, como fruto do caráter inercial das políticas públicas urbanas (Marques e Najar, 1995; Torres, 1997). Aparentemente, os dados de segregação caminham no sentido de reafirmar, para a década de 1990, paradoxo análogo.

Em outras palavras, embora a ação estatal tenha contribuído nas últimas décadas para reduzir a desigualdade em termos de acesso a serviços públicos - particularmente educação e saneamento -, essas intervenções não contribuíram para reduzir de modo significativo o grau de isolamento entre os grupos sociais existentes em São Paulo. Os níveis de segregação já eram elevados em 1991 e cresceram na última década.

Aparentemente, uma das poucas políticas sociais que poderia ser utilizada de modo consistente para combater a segregação residencial - embora 
possa agravá-la - é a política habitacional (Briggs, 2001). ${ }^{30}$ Infelizmente, essa política parece ter sido pouco prioritária, tanto na agenda nacional como local na década de 1990. ${ }^{31}$ Enquanto volumes significativos de recursos eram alocados - inclusive mediante reformas constitucionais - para as áreas de saúde e educação, os recursos para a área de habitação ficaram relativamente contingenciados, até mesmo devido aos problemas observados com o FGTS nos anos de 1990.

De modo geral, políticas habitacionais - sobretudo aquelas voltadas para os grupos de menor renda - precisam ser subsidiadas. Esse elemento, somado ao elevado déficit habitacional, ${ }^{32}$ pode ter desencorajado programas habitacionais em larga escala, sobretudo num contexto de severa restrição orçamentária. De qualquer maneira, ainda precisamos entender em profundidade por que as políticas habitacionais avançaram lentamente na década, quando outras políticas sociais apresentaram resultados mais significativos.

Num artigo publicado na imprensa,,$^{33}$ por exemplo, o presidente da Caixa Econômica Federal ao longo do Governo Fernando Henrique Cardoso (Emílio Carazzai) argumentava que os mecanismos de crédito não subsidiado não eram adequados para as famílias que recebiam menos de três salários mínimos. Além disso, o programa público mais importante na área (Programa de Arrendamento Residencial - PAR) naquele momento não podia ser adequadamente implantado em regiões metropolitanas em função da inadequação do valor dos financiamentos aos altos custos dos terrenos existentes nas metrópoles.

Em tese, as restrições orçamentárias poderiam ser parcialmente contornadas por meio de políticas habitacionais não convencionais, tais como a urbanização de favelas, a regularização fundiária e a readequação de cortiços. Essas políticas podem ter impactos importantes porque são muito mais baratas e podem envolver aspectos de desenvolvimento comunitário. No entanto, elas contribuem pouco para a redução da segregação residencial porque, em geral, não produzem uma maior "mistura populacional".

Em síntese, a necessidade de uma política habitacional capaz de combater a segregação residen- cial e suas conseqüências parece ser uma prioridade evidente para uma região metropolitana como a de São Paulo, onde o crescente sentimento de malestar coletivo, violência e degradação urbana é a manifestação mais aparente do fenômeno. Porém, a prioridade política, bem como as condições institucionais e financeiras de tal política não parecem ter sido viabilizadas na última década.

\section{Notas}

1 Exceções são os trabalhos de Edward Telles (1994, 1995 e 2003).

2 Por macrosegregação consideramos o fenômeno numa escala espacial mais abrangente, como distritos censitários. Por microsegregação, tomamos os setores censitários como unidade de análise. Em termos empíricos, pode-se observar distinções importantes entre esses fenômenos, com a redução da macrosegregação em uma determinada área urbana e o aumento da microsegregação, como ocorrido em Santiago recentemente (Sabatini, 2001).

3 A renda familiar per capita seria a variável mais adequada para medirmos as dimensões socioeconômicas da segregação residencial. Infelizmente, o IBGE não publica essa variável na escala de setores censitários, inviabilizando sua utilização como medida de microsegregação.

4 Na América Latina muitas vezes esse conceito tem sido utilizado de modo frouxo, assumindo que a segregação espacial é um mero reflexo das diferenças sociais. O termo segregação é também tomado como sinônimo de desigualdade, exclusão e mesmo de pobreza (Sabatini, 2001).

5 "Segregação é o processo pelo qual a população é forçada - isto é, de modo involuntário - a se concentrar em uma área específica, num ghetto. Tratase do processo de formação e manutenção desse ghetto" (Marcuse, 2001)

6 Por mais interessante e rigorosa que seja essa definição, a identificação do quanto a segregação de uma determinada área é forçada ou voluntária é praticamente impossível do ponto de vista das medidas convencionais do fenômeno. É inevitável utilizar dados etnográficos para se identificar, por exemplo, se as famílias que residem numa dada área o fazem, ou não, por falta de opção. Em outras palavras, as medidas de segregação, que normalmente se baseiam em dados agregados por áreas, permitem observar os níveis de segregação e sua variação ao longo do tempo, mas não permitem qualificar sua natureza (forçada, auto-segregação etc.). 
7 Essa discussão é baseada em parte em Yinger (2001).

8 Por exemplo, uma parcela significativa das favelas de São Paulo está localizada em locais de risco ambiental (Taschner, 1992).

9 Esse efeito seria ainda maior se a moradia em terreno ocupado (como em favelas) não existisse.

10 Tal possibilidade é menos freqüente no Brasil em função da legislação que veda o despejo de famílias possuidoras de um único imóvel próprio.

11 Massey e Denton (1993) mencionam outras dimensões, tais como concentração (que mede a densidade da pobreza) e centralização (que mede sua localização em relação ao centro da cidade). Consideramos esses elementos menos relevantes para a discussão brasileira.

12 Em termos formais, o índice de dissimilaridade pode ser descrito por: ID $=0,5 \hat{\mathrm{A}} \sim \mathrm{Xi}-\mathrm{Yi}^{\sim}$, onde $\mathrm{Xi}$ é a proporção de membros do grupo $\mathrm{X}$ residentes no distrito $i$ (em relação ao total de pessoas do grupo X no município) e Yi é a proporção de membros do grupo Y residentes no distrito $i$ (em relação ao total de pessoas do grupo Y no município).

13 Esta última característica tende a tornar mais complexas as comparações interáreas pois, para que a comparação seja realizada adequadamente, o tipo de unidade de análise tem de ser relativamente homogêneo nas duas localidades observadas.

14 Infelizmente o IBGE não publica, na escala de setores censitários, os dados de raça ou cor.

15 Devido à disponibilidade de dados por setor censitário, consideramos nesta análise os 21 municípios que formam a mancha urbana de São Paulo e contribuem com mais de $92 \%$ da população total da região metropolitana. Grosso modo, excluímos municípios de pequeno porte e predominantemente rurais como Santa Isabel, Juquitiba e Salesópolis. Todos os municípios de grande porte, como São Paulo, Osasco, Guarulhos e os da região do ABCD foram considerados.

16 Os ganhos salariais do Plano Real passaram a ser comprometidos a partir de 1998. Todavia, em 2000 os níveis observados eram significativamente superiores aos de 1991, sobretudo em função da redução da inflação.

17 Considerando os dados da Pesquisa de Emprego e Desemprego (PED-Seade/Dieese) - para a qual não há variação na forma de captação da informação sobre os "sem rendimento" -, a proporção de chefes de domicílio com renda entre zero e três salários mínimos passou de 44,4\% em setembro de 1991 (data do censo) para 31,0\% em julho de 2000.

18 O fato de o número de setores censitários não ser idêntico entre os dois censos pode distorcer em al- guma medida a comparação aqui realizada. Apresentamos no Anexo 1 os mesmos dados para agrupamentos de setores censitários comparáveis nos dois censos. Os resultados aí observados são bastante similares, e as conclusões apontam para a mesma direção.

19 Nesse estudo, os autores consideram também a escala de setores censitários para produzir os indicadores de segregação. No entanto, os setores censitários norte-americanos têm tamanho superior aos brasileiros, com aproximadamente quatro mil habitantes por área. Em contrapartida, segregação racial e socioeconômica não são necessariamente comparáveis diretamente.

20 Esses dados são consistentes com estudos recentes. Há evidência de que a principal barreira à ascensão educacional existente na escola brasileira hoje, particularmente em São Paulo, encontra-se agora na passagem do segundo grau para a universidade (Menezes-Filho, 2002).

21 Ver na seção "Segregação e políticas públicas" a discussão sobre o problema do grid.

22 Essa hipótese parece sugerir o aumento da microsegregação (na escala de setores censitários), mas não necessariamente o da macrosegregação.

23 Embora os números envolvidos nesta área sejam polêmicos, sobretudo em função de estimativas sobre-registradas de população favelada realizadas pela Fipe (Diário Oficial do Município de São Paulo, 1995), tudo indica que tem havido um aumento consistente da proporção população que reside em favelas desde os anos de 1970 (Torres e Marques, 2002). Entre 1991 e 2000, a população residente nos chamados setores censitários subnormais - o conceito de favelas do IBGE - cresceu a uma taxa de $3,7 \%$ ao ano, contra um crescimento de $0,9 \%$ para o conjunto do município.

24 Distritos como Grajaú, Jaraguá e Cidade Tiradentes cresceram a mais de 4\% ano entre 1991 e 2000.

25 Por predominantemente de zero a três salários mínimos, por exemplo, entendemos que este setor tem um maior número de chefes de zero a três salários mínimos do que de chefes de três a dez salários mínimos ou de dez salários mínimos e mais.

26 Este resultado é afetado pelo recorte especial adotado. Num exercício análogo, onde adotamos um outro recorte especial que considerava simultaneamente renda familiar e taxa de crescimento demográfico, a proporção dos mais ricos residindo em áreas com predomínio de famílias de renda mais elevada ficou estável.

27 A proporção de famílias nas áreas com predomínio de pobres passou de 22,1 para 22,8\% do total da mancha urbana. 
28 Em termos matemáticos, trata-se da forma $0,5 \hat{\mathrm{A}}^{\sim} \mathrm{Xi}$ - Yi ${ }^{\sim}$, para uma dada sub-região da cidade. Ver seção "Segregação e políticas públicas".

29 Ver, por exemplo, Faria (1992) e Silva (1992).

30 As políticas de zoneamento urbano e de taxação da renda da terra também podem, em tese, ser mobilizadas com este objetivo.

31 Uma possível exceção é o governo de Luiza Erundina na prefeitura de São Paulo.

32 O déficit habitacional brasileiro foi estimado em seis milhões de moradias em 2000 (FJP, 2000).

33 Ver, Valor Econômico, 3 abr. 2002, p. A12.

\section{BIBLIOGRAFIA}

ALESP, (2000), Cadernos do fórum São Paulo: século XXI. São Paulo, Alesp.

BONDUKI, N. \& ROLNIK, R. (1982), "Periferia da Grande São Paulo: reprodução do espaço como expediente de reprodução da força de trabalho", in E. Maricato (org.), A produção capitalista da casa (e da cidade) do Brasil industrial. São Paulo, Alfa-ômega.

BRIGGS, Xavier S. (2001), "Ties that bind, bridge, and constrain: social capital and segregation in American Metropolis". Trabalho apresentado no International Seminar on Segregation and the City, Cambridge, Lincoln Institute of Land Policy, jul. (www.lincolninst.edu).

CALDEIRA, Teresa, P. (2000), A cidade dos muros. São Paulo, Editora 34/Edusp.

CARDIA, N. (1999), "Os impactos da exposição à violência: aceitação da violência ou horror continuado? O caso de São Paulo". Trabalho apresentado no Encontro "Culture, Citizenship and Urban Violence", México, Cuernavaca.

. (2000), "Urban violence in São Paulo". Comparative Urban Studies Occasional Papers Series, 33, Washington, D.C., Woodrow Wilson International Center for Scholars.
CEPAL. (2002), Panorama social de América Latina, 2000-2001. Santiago, Cepal.

DIÁRIO Oficial do Município de São Paulo. (1995), "Favelas na Cidade de São Paulo". Diário Oficial, edição especial, 101, 31 mar.

DURLAUF, S. N. (2001), "The membership theory of poverty: the role of group affiliations in determing socioeconomic outcomes", in S. H. Danziger e R. H. Haverman, Understanding poverty, Nova York, Russell Sage, pp. 392-416.

EMPLASA. (1994), Plano metropolitano da Grande São Paulo. São Paulo, Emplasa.

FARIA, V. (1992), "A conjuntura social brasileira: dilemas e perspectivas". Novos Estudos Cebrap, 33

FJP. (2000), Déficit habitacional no Brasil. Brasília, Secretaria Nacional de Políticas Urbanas/PNUD (www.pbqp-h.gov.br/deficit2000/apresentacao.htm).

KAPLAN, Robert D. (1996), The end of the earth: a journey at the dawn of the $21^{\text {st }}$ century. Nova York, Random House.

KASARDA, J. D. (1993), "Inner-city poverty and neighborhood distress: 1970-1990". Housing Policy Debate, 4 (3): 253-302.

KOWARICK, L. (1979), A espoliação urbana. Rio de Janeiro, Paz e Terra.

(2003). "Sobre a vulnerabilidade socioeconômica e civil: Estados Unidos, França e Brasil". Revista Brasileira de Ciências Sociais, 51.

LOGAN, J. (2000), "Still a global city: the racial and ethnic segmentation of New York", in P. Marcuse e R. Kempen, Globalizing cities: a new spatial order?, Londres, Blackwell.

MARCUSE, P. (2001), "Enclaves yes, ghettoes, no: segregation and the State". International Seminar on Segregation and the City, Cambridge, Lincoln Institute of Land Policy. 
MARICATO, E. (1996), Metrópole na periferia do capitalismo: ilegalidade, desigualdade e violência. São Paulo, Hucitec.

MARQUES, E. \& BITAR, S. (2002), "Grupos sociais e espaço". Novos Estudos Cebrap, 64: 123-131 (Dossiê Espaço, Política e Políticas na Metrópole Paulistana).

MARQUES, E. \& NAJAR, A. (1995), "Espaço e mortalidade no Rio de Janeiro da década de 1980". Anais do VI Encontro Nacional da Anpur, Brasília.

MASSEY, D. S. \& DENTON, N. A. (1993), American apartheid: segregation and the making of the underclass. Cambridge, Harvard University Press.

MENEZES-FILHO, N. A. (2002), "A evolução da educação no Brasil e seu impacto no mercado de trabalho. São Paulo", FEA/USP (mimeo).

MINGIONE, Enzo. (1999), "Urban poverty in the advanced industrial world: concepts, analysis and debates", in E. Mingione (ed.), Urban poverty and the underclass, Nova York, Blackwell.

RIBEIRO, L. C. \& Telles, E. (2000), "Rio de Janeiro: emerging dualization in a historically unequal city", in P. Marcuse e R. Kempen, Globalizing cities: a new spatial order?, Londres, Blackwell.

ROLNIK, R. (1997), A cidade e a lei: legislação, política urbana e territórios na cidade de São Paulo. São Paulo, Nobel/Fapesp.

SABATINI, F. (2001), "Residencial segregation pattern changes in Chile's main cities: scale shifts and increasing malignancy". International Seminar on Segregation and the City, Cambridge, Lincoln Institute of Land Policy.

SANTOS, C. (1982), Processo de crescimento $e$ ocupação da periferia. Rio de Janeiro, Ibam/CPU.

SANTOS, W. G. (1987), "A trágica condição da política social", in S. Abranches; W. dos Santos e M. Coimbra, Política social e combate à pobreza, Rio de Janeiro, Jorge Zahar.
SCHTEINGART, M. (1987), "Estrutura urbana y la diferenciación socio-espacial en la zona metropolitana de la Ciudad de México (1970-1980)". Revista Del Colégio de México, s. n.

SILVA, L. (org.). (1992), o que mostram os indicadores sociais sobre pobreza na década perdida. Rio de Janeiro, Ipea (relatório de pesquisa).

SMOLKA, M. (1987), "Para uma reflexão sobre o processo de estruturação interna das cidades brasileiras: o caso do Rio de Janeiro". Espaço e Debates, 21.

TASCHNER, S. P. (1992), "Degradação ambiental em áreas de invasão no município de São Paulo". Anais do VIII Encontro Nacional de Estudos Populacionais, São Paulo, Abep.

TASCHNER, S. P. \& BÓGUS, L. (2000), "A cidade dos anéis: São Paulo", in L. C. Queiroz (ed.), O futuro das metrópoles: desigualdades e governabilidade, Rio de Janeiro, Revan/Fase.

TELLES, E. (1994), "Residencial segregation by skin color in Brazil". American Sociological Review, 57 (2): 186-197, abr.

(1995), "Structural sources of socioeconomic segregation in Brazil". American Journal of Sociology, 100 (5): 199223.

(2003), "U.S. Foundations and racial reasoning in Brazil". Theory, Culture $\&$ Society, 20 (4).

TORRES, H. (1997), Desigualdade ambiental em São Paulo. Tese de doutorado, Campinas, IFCH.

TORRES, H. (2002), "Social policies for the urban poor: the role of population information". Working Papers Series CST/ LAC, 24, UNFPA Country Support Team for Latin America and the Caribbean.

TORRES, H. \& MARQUES, E. (2002), "Tamanho populacional das favelas paulistanas: ou os grandes números e a falência do de- 
bate sobre a metrópole". Trabalho apresentado no encontro Nacional de Estudos Populacionais, Ouro Preto, Abep.

(2001), "Reflexões sobre a hiperferiferia: novas e velhas faces da pobreza no entorno metropolitano". Revista Brasileira de Estudos Urbanos e Regionais, 4.

VALLADARES, L. \& COELHO, M. (1995), "Urban research in Brazil and Venezuela: towards an agenda for the 1990s", in P. Stren (ed.), Urban research in the developing world - Latin America, Toronto, Center for Urban and Community Studies.

VILLAÇA, F. (1999), "Efeitos do espaço sobre o social na metrópole brasileira", in M. A. Souza (ed.), Metrópole e globalização: conhecendo a cidade de São Paulo, São Paulo, Cedesp.

(2001), Espaço intra-urbano no Brasil. São Paulo, Nobel/Fapesp.

WILSON, William. (1990), The truly disadvantaged: the inner city, the underclass and public policy. Chicago, University of Chicago Press.

WORLD BANK. (1999), Entering the $21^{\text {st }}$ century: world development report, 1999-2000. Oxford, Oxford University Press.

YIENGER, J. (2001), "Housing discrimination and residential segregation as causes of poverty", in S. H. Danziger e R. H. Haverman, Understanding poverty, Nova York, Russell Sage, pp. 359-391.

\section{Anexo 1}

Este anexo apresenta os índices de dissimilaridade para 1991 e 2000 para grupos de setores censitários compatíveis espacialmente nos dois censos. Para compatibilizar os setores, trabalhamos - no âmbito de um sistema de informações geográficas - com o critério de áreas mínimas comparáveis, agregando, por exemplo, os setores subdivididos entre os dos censos.

Tabela 6

Índices de Segregação Residencial (Dissimilaridade) Segundo Diferentes Grupos de Escolaridade e Renda, na Escala de Setores Censitários Compatibilizados para 1991 e 2000, Mancha Urbana de São Paulo*

\begin{tabular}{lll}
\hline Dissimilaridade Residencial & 1991 & 2000 \\
\hline Dissimilaridade entre chefes de 0 a 3 e 10 e mais salários mínimos & 56,81 & 60,08 \\
Dissimilaridade entre chefes de 0 a 3 e 15 e mais salários mínimos & 65,37 & 68,16 \\
Dissimilaridade entre chefes de 0 a 3 e 20 e mais salários mínimos & 70,43 & 74,43 \\
Dissimilaridade entre chefes de 0 a 3 e 11 e mais anos de estudo & 55,69 & 49,52 \\
Dissimilaridade entre chefes de 0 a 3 e 15 e mais anos de estudo & 68,94 & 69,03 \\
Total de áreas consideradas (setores compatibilizados) & 11.347 & 11.353 \\
\hline
\end{tabular}

*As estimativas de dissimilaridade foram realizadas a partir dos setores censitários de 1991 e 2000.

Fonte: IBGE, Censos Demográficos de 1991 e 2000. 


\section{SEGREGAÇÃO RESIDENCIAL E POLÍTICAS PÚBLICAS:} São Paulo na Década de 1990

Haroldo da Gama Torres

\section{Palavras-chave}

Sociologia urbana; Segregação; Planejamento urbano; Pobreza; Desigualdade social.

Este artigo pretende medir a evolução da segregação residencial na região metropolitana de São Paulo na década de 1990. Os resultados obtidos indicam que a segregação socioeconômica aumentou substancialmente em São Paulo ao longo dessa década. Além de interpretar esse fenômeno, propomos uma discussão a respeito do por quê a segregação residencial deve ser considerada um elemento fundamental para a formulação de políticas sociais urbanas.

\section{RESIDENTIAL SEGREGATION AND PUBLIC POLICIES: São Paulo in the 1990's}

Haroldo da Gama Torres

\section{Keywords}

Urban sociology; Segregation; Urban planning; Poverty; Social unevenness.

The article aims at assessing the evolution of residential segregation in the metropolitan area of São Paulo, Brazil, in the 1990's, which saw a significant increase of socioeconomic segregation. In addition to interpreting the phenomenon, the article proposes a discussion on the reasons the residential segregation should be considered a fundamental issue for the formulation of social urban policies.

\section{SÉGRÉGATION RÉSIDENTIELLE ET POLITIQUES PUBLIQUES: São Paulo dans les années 1990}

Haroldo da Gama Torres

\section{Mots-clés}

Sociologie urbaine; Ségrégation; Planification urbaine; Pauvreté; Inégalité sociale.

Cet article analyse l'évolution de la ségrégation résidentielle dans la région métropolitaine de São Paulo dans les années 1990. Les résultats obtenus indiquent que la ségrégation socio-économique a substantiellement augmenté à São Paulo tout au long de cette décennie. Dans cet article, nous interprétons ce phénomène et proposons également une discussion à propos de la raison pour laquelle la ségrégation résidentielle doit être considérée comme un élément fondamental pour la formulation de politiques sociales urbaines. 